\title{
Prefrontal dopamine D1 receptor manipulation influences anxiety behavior and induces neuroinflammation within the hippocampus
}

Dominik K E Beyer

Ruhr University https://orcid.org/0000-0002-3297-8236

Annika Mattukat

Ruhr University

Nadja Freund ( $\sim$ Nadja.freund@rub.de)

\section{Research}

Keywords: bipolar disorder, interleukin-6, anxiety, lentivirus, prefrontal cortex, rat

Posted Date: May 8th, 2020

DOI: https://doi.org/10.21203/rs.3.rs-25001/v1

License: (a) (i) This work is licensed under a Creative Commons Attribution 4.0 International License. Read Full License 


\section{Abstract}

Background - Prefrontal dopamine D1 receptor (D1R) mediates behavior related to anxiety, reward and memory, and is involved in inflammatory processes, all of which are affected in bipolar disorder. Patients with bipolar disorder show alternations in the dopamingergic and immune system. Interleukin-6 (IL-6), a pro-inflammatory cytokine, is increased in plasma samples, imaging studies and post mortem tissue. Manipulation of the D1R in the medial prefrontal cortex (mPFC) e.g. results in BD-like behavior. The purpose of the study is the investigation of the influence of D1R over-expression and its termination on the immune system and anxiety behavior in rats.

Methods - Expression of the gene for D1R in glutamatergic neurons within the MPFC of male, adult rats was manipulated through an inducible (Tet.On) lentiviral vector. Anxiety behavior was studied in the elevated plus maze and marble burying test in 'ON' (D1R over-expression) and 'OFF' (termination of D1R over-expression) states. IL-6-positive cells were counted to identify the inflammatory state within several subregions of the hippocampus.

Results - D1R 'OFF' subjects buried more marbles compared to D1R 'ON' and their respective control animals indicating an increased anxiety behavior. D1R 'OFF' animals reflected an elevated proinflammatory state in the hippocampus, in the CA3 and dentate gyrus especially. Consistently, inflammatory state in the whole hippocampus and anxiety behavior correlated positively, indicating a connection between anxiety and inflammatory state of the hippocampus.

Conclusions - Behavioral and molecular findings support the association of D1R's impact on anxiety and inflammation. In addition, by confirming an involvement of IL-6, the new animal model for bipolar disorder has been further validated.

\section{Background}

Neuroinflammation describes the inflammatory response in the brain that is mediated by glia cells, endothelial cells, and peripherally derived immune cells of the central nervous system. These inflammatory processes are a protective reaction of the organism e.g. to fight bacterial infections and are mediated by the production of cytokines, chemokines, reactive oxygen species, and secondary messengers (DiSabato et al. 2016; Xia et al. 2019). Dysregulated and chronic neuroinflammation can result in disruptions of the blood-brain barrier (Lochhead et al. 2017), decreased synaptic plasticity (Riazi et al. 2015) and even neurodegenerative disorders, such as Alzheimer's disease (Schain and Kreisl 2017), Multiple sclerosis (Filippi et al. 2018), abnormal anxiety behavior (Michopoulos et al. 2017), and severe psychiatric disorders, like schizophrenia (Na et al. 2014), major depression disorder (MDD) (Leonard 2014) and bipolar disorder (BD) (Goldsmith et al. 2016b; Modabbernia et al. 2013). Interestingly, schizophrenia (Gründer and Cumming 2016), MDD (Nutt 2008) and BD are all linked to dysregulated dopamine (DA) signaling. In addition, the relationship of DA, DA receptors and inflammation is widely known (Xia et al. 2019). In summary, DA and its receptors are able to regulate the immune system in an 
activating and inhibiting manner (Han et al. 2017; Sarkar et al. 2010; Zhang et al. 2016). One of those immunoregulatory DA receptors is the dopamine D1 receptor (D1R). DA and D1R signaling via the second messenger cyclic adenosine monophosphate (CAMP) prevent nucleotide-binding oligomerization domainlike receptor pyrin domain-containing 3 (NLRP3) inflammasome-dependent inflammation, including lipopolysaccharide (LPS)-induced systemic inflammation and neurotoxin-induced neuroinflammation in vivo (Yan et al. 2015). One key mechanism of action of DA receptors are related to inhibition of the NF-KB pathway (Han et al. 2017). In addition to its role in immune regulation, D1R functionality is crucial for formation of spatial working learning and memory processes through regulation of brain-derived neurotrophic factor (BDNF) expression in the prefrontal cortex (PFC) (Xing et al. 2012). D1R in the medial prefrontal cortex mPFC mediates anxiety behavior in rodents (Liu et al. 2019a).

In summary, DA is able to modify inflammation through several pathways. In addition, alterations of the immune system can result in abnormal anxiety behavior (Michopoulos et al. 2017). Investigation of inflammatory mediators, such as cytokines, acute phase proteins, and T cell-related activation markers, can be informative about the inflammatory state of the individual. Cytokines act as key signaling molecules of the immune system mediating effects in the brain and periphery. These small proteins are produced by immune and non-immune cells, and act via binding to specific receptors on a variety of target cells. Cytokines are key regulators of acute and chronic inflammation. One prominent proinflammatory cytokine is interleukin-6 (IL-6). IL-6 signaling plays a pivotal role in inflammatory processes (Neurath and Finotto 2011) with wide-ranging consequences even on behavioral level (Felger 2018). The immune system can directly influence the individual's mood. Indeed, induction of inflammation can lead to sad mood in humans (Reichenberg et al. 2001) and sickness behavior in rodents, representing depression-like symptoms, such as low mood, anhedonia, anorexia and weight loss (D'Mello et al. 2015; Fu et al. 2010). This is not surprising considering the potentially evolutionary benefit of behavioral responses to inflammation: decreased motivation and motor activity to support the containment of pathogens and the initiation of recovery (Raison and Miller 2013). Chronic inflammatory processes, however, can cause severe side effects in the brain. For example, a persistent and low-grade proinflammatory state is present in BD patients (Brietzke et al. 2009b; Goldsmith et al. 2016b; Lu et al. 2019; Modabbernia et al. 2013). This chronic low-grade inflammation is characteristic for affective disorders and anxiety-related disorders, such as generalized anxiety disorder and post-traumatic stress disorder, too (Goldsmith et al. 2016b; Haroon et al. 2012; Michopoulos et al. 2017). These findings are supported by the evidence, that adjunctive treatment with some anti-inflammatory agents is able to alleviate manic and improve depressive symptoms (Ayorech et al. 2015; Goldsmith et al. 2016b; Köhler et al. 2014; Miller et al. 2017; Rosenblat 2019). Whereas anti-inflammatory agents primarily improved motivation and anxiety (Raison et al. 2013). In addition, induction of depression-like behavior via learned helplessness paradigm resulted in an increased IL-6 expression within the hippocampus (Onufriev et al. 2017). Ketamine's antidepressant effect might be through its ability to reduce cytokines in the hippocampus, thus functioning anti-inflammatory (Wang et al. 2015). Thereby connecting increased inflammatory states within the hippocampus with depression-like behavior. 
The relationship between DA, its receptors and the immune system is bidirectional. Indeed, immune system activation and the resulting release of inflammatory cytokines can negatively affect reward behavior, motivation, anxiety and DA, which can be identified as depression-like behavior in animals (Fischer et al. 2015; Kamata et al. 2000; Kaster et al. 2012; Kitagami et al. 2003; Makino et al. 2000; Remus and Dantzer 2016; Shuto et al. 1997; Simen et al. 2006; Wachholz et al. 2017) and depressive symptoms in patients (Capuron et al. 2012; Capuron et al. 2007; Eisenberger et al. 2010; Goldsmith et al. 2016a; Majer et al. 2008). Nevertheless, to our knowledge no induction of mania-like behavior via activation of the immune system have been reported yet (Beyer and Freund 2017; van Enkhuizen et al. 2015; Kato et al. 2007; Logan and McClung 2016; Sharma et al. 2016). Nonetheless, other animal models of mania, e.g. through amphetamine administration, exhibited increased plasma and brain cytokine levels (Valvassori et al. 2015). In summary, the immune system and dopaminergic system are closely interlinked.

As mentioned before, more and more evidence suggests that aberrations in the immune system with its immune-inflammatory pathways contribute to the pathophysiology of psychiatric disorders including BD. BD patients exhibit a persistent and low-grade pro-inflammatory state. This pro-inflammatory state is even more intense during mood episodes, especially manic episodes, and less intense in depressive episodes (Brietzke et al. 2009b; Lu et al. 2019; Modabbernia et al. 2013). These findings are supported by phasic differences in the peripheral levels of cytokines in BD patients (Ortiz-Domínguez et al. 2007). Furthermore, even euthymic episodes are associated with increased peripheral pro-inflammatory cytokines (Brietzke et al. 2009a; Brietzke et al. 2009b). Interestingly, cytokine levels did not differ between patients in remission and healthy controls (Brietzke et al. 2009b). Overall, abnormalities of the immune system have been linked to symptom severity (Goldstein et al. 2009; Tsai et al. 2001), state of mood episodes (Brietzke et al. 2009b; Ortiz-Domínguez et al. 2007) and treatment effect (Benedetti et al. 2017; Boufidou et al. 2004; Goldstein et al. 2009; Guloksuz et al. 2012; Knijff et al. 2007; Modabbernia et al. 2013).

Here, we used an animal model, which is capable of inducing mania- and depression-like behavior within the same rat in an alternating manner. Viral D1R over-expression in the mPFC of rats resulted in manialike behavior (Freund et al. 2016; Sonntag et al. 2014). Termination of viral D1R over-expression alone was sufficient to induce depression-like behavior (Freund et al. 2016). To investigate an aberrant activation of the immune system in this model, we analyzed the number of IL-6-positive cells in the hippocampus. We furthermore evaluated if anxiety in this model is correlated with IL-6-positive cells.

\section{Methods}

\subsection{Animals}

A total of $n=24$ adult, male Sprague Dawley rats were obtained from Charles River Laboratories (Sulzfeld, Germany). Rats were pair-housed ( 2 animals per cage) in a standard cage with food and water available ad libitum in constant temperature and humidity conditions $\left(22 \pm 2{ }^{\circ} \mathrm{C}\right.$ and $\left.55 \pm 25 \%\right)$ on a 12 -h 
light/12-h dark cycle (light period 21:00-11:00). The animals were allowed to acclimate to the animal facility for 1 week before surgery. Only males were used in order to avoid an influence of the estrous cycle on dopaminergic processes within the PFC, nucleus accumbens and striatum of female rats. All experiments were carried out in agreement with the principles regarding the care and use of animals adopted by the German Animal Welfare Law for the prevention of cruelty to animals after approval by the LANUV (Landesamt für Natur, Umwelt und Verbraucherschutz Northrhine-Westfalia).

\subsection{Lentiviral vector}

\subsubsection{Virus production}

The same lentiviral construct was used as previously described (Freund et al. 2016). In short, a Tetracycline-On inducible lentiviral vector system (Tet.On) was used, coding for the rat D1R protein (DRD1 gene) or for control condition for the red fluorescent protein dsRed. The system, was driven by a CamKIla promoter to constitutively drive rtTA3 expression and dsRed or D1R expression was regulated by the tetracycline derivative doxycycline (DOX). Virus production was performed by the Viral Core Facility, Charité Universitätsmedizin Berlin based on the protocol of Stewart and colleagues (Stewart et al. 2003) with the use of plasmids 8454 and 8455 by Addgene.

\subsubsection{Surgery}

Rats were anesthetized with ketamine/xylazine/azaperone mixture (100/16/8 mg/kg) and $1 \mu \mathrm{l}$ of virus (2 $\times 10^{7}$ transducing units per $\mu \mathrm{l}$ ) were bilaterally injected into the mPFC at stereotaxic coordinates (AP: +2.7, ML: \pm 0.4 , DV: -2.8 ) of rat brain atlas (Paxinos et al. 1980).

\subsubsection{Doxycycline treatment}

The virus system can be controlled through administration of DOX hyclate (Sigma-Aldrich). Virus expression was activated by $0.5 \mathrm{~g} / \mathrm{I} \mathrm{DOX}$ in the drinking water to produce an 'ON' state. As previously shown, full viral expression occurred within seven days after DOX administration ('ON' state) and viral over-expression was reduced three days after DOX removal ('OFF' state) (Freund et al. 2016). 'ON' group received in total 15 days of DOX through drinking water, whereas the 'OFF' group was given DOX for 7 days followed by 8 days of regular drinking water without DOX (Fig. 1).

After virus injection, rats received 7 continuous days of DOX to induce virus over-expression. Virus overexpression was maintained in one half of the subjects till their sacrifice. This group is referred to as 'ON' group and demonstrated mania-like behavior in previous experiments (Freund et al. 2016). The 'OFF' group received 7 days of DOX following DOX removal till immunohistochemistry. These subjects demonstrated depression-like behavior (Freund et al. 2016). Anxiety-related behavior was investigated in both groups on day 11 via elevated plus maze and through marble burying on day 12 of DOX treatment. Subjects were sacrificed on day 15.

\subsection{Behavioral Assessments}




\subsubsection{Elevated Plus Maze (EPM)}

EPM was performed on day 11. The EPM is a paradigm to test anxiety of animals, consists of two open and closed arms (each $15 \times 42.5 \mathrm{~cm}$ ) and was raised $72.5 \mathrm{~cm}$ from the floor. Tests were performed during the dark phase of the light-dark cycle. Each subject, experimentally naïve, was placed in the central platform of the maze, facing a closed arm, and allowed to freely explore the maze for $5 \mathrm{~min}$. Time spent in the open and closed arms were recorded for $5 \mathrm{~min}$. Scoring was performed by an investigator blinded in terms of experimental conditions.

\subsubsection{Marble burying test (MB)}

Marble burying test was performed on day 12. This paradigm is also able to investigate anxiety and compulsive activity of the subjects. Marble burying test was performed during dark phase of the lightdark cycle in unfamiliar standard cages, containing a $5 \mathrm{~cm}$ layer of bedding. Twenty marbles were evenly placed in rows on the surface of the bedding. Rats were placed in the cage for $15 \mathrm{~min}$. The number of totally buried $(100 \%)$ and unburied marbles were counted for each rat from a blind investigator.

\subsection{Immunohistochemistry (IHC), cell counting and analysis of IL-6 staining}

For IHC rats were deeply anesthetized with a ketamine/xylazine mixture $(100 / 10 \mathrm{mg} / \mathrm{kg})$ and intracardially perfused with $4 \%$ paraformaldehyde as previously described (Gage et al. 2012). The brains were cryoprotected and cut into $40 \mu \mathrm{m}$ coronal sections. After blocking in 10\% normal goat serum, sections were exposed overnight at $4{ }^{\circ} \mathrm{C}$ to 1:300 rabbit anti-IL-6 (Proteintech), washed in 1x PBS, and incubated for $60 \mathrm{~min}$ at room temperature with anti-rabbit Alexa 488-coupled IgG (Sigma-Aldrich). Sections were washed, incubated with 1:1000 of a $20 \mathrm{mg} / \mathrm{ml}$ stock solution of 4',6-diamidino-2phenylindole (DAPI), washed, and mounted on slides. Images of the regions of interest within the hippocampus (bregma - $2.76 \mathrm{~mm}$ ) (Fig. 2A) were generated with a fluorescence microscope (Olympus BX51) and the software CellD under consistent exposure time. Each region of interest (hippocampal CA1, CA2, CA3, CA4, DG) were adapted to an image size of $300 \times 900$ pixels via GIMP (version 2.10.14). IL-6positive cells were identified as an completely filled cell with fluorescence signal (Fig. 2B).

Cells were counted manually by an investigator blinded in terms of experimental conditions with ImageJ (Schindelin et al. 2012).

\subsection{Statistics}

Statistics were performed with SPSS statistical software 26 (version 26.0.0.0). Data are depicted as means and SEMs. Behavioral data was analyzed with a two-way multivariate analysis of variance (MANOVA) with virus group and virus state as factors. Immunohistochemistry including cell counting of IL-6 and DAPI-positive cells were analyzed via repeated measurements ANOVA with two between-subjects factors: virus group and virus state. Then, cell counts were analyzed via MANOVA. Post-hoc comparison was performed in all cases via Bonferroni corrected independent $t$ test. Correlation between IL- 6 
immunoreactivity and anxiety behavior was assessed with Pearson correlation coefficients. Experimenters were blind to treatment of animals during experimental and data collection processes. In all cases, $p<0.05$ was considered as statistically significant.

\section{Results}

\subsection{Elevated Plus Maze}

Animals transduced with either D1R or dsRed were tested in the EPM either in the 'ON' or 'OFF' state of virus over-expression (Fig. 3A-C). No interaction of virus group and virus state on time spent in the open arms were observable $(F(1,20)=0.014, p=0.9)(F i g .3 A)$. The virus state has a significant effect on open arm entries $(F(1,20)=28.167, p=0.028)$. Post hoc comparison revealed a decreased anxiety behavior, indicated through more open arm entries in the 'ON' group (Bonferroni correction, $p<0.05$ ). Whereas no significant virus state $X$ virus group interaction for open arm entries was present $(F(1,20)=8.167, p=$ 0.21 ) (Fig. 3B). A different significant virus group $X$ virus state interaction on time till first entry into open arm was also found $(F(1,20)=4,378, p=0.049)$. This result, however, was not able to withstand post-hoc comparison via Bonferroni correction between all groups (Bonferroni correction, $p>0.05$ ) (Fig. 3C). Taken together, D1R over-expression in the mPFC had only a mild influence on anxiety. Termination of D1R overexpression resulted in an increased latency till first open arm entry and decreased number of open arm entries.

\subsection{Marble burying}

Marble burying test was used to investigate anxiety and compulsive activity in the same subjects. At first, the injected virus has a significant effect on the amount of buried marbles $(F(1,20)=84,375, p=0.036)$. Post-hoc comparison revealed, that D1R animals buried significantly more marbles than dsRed animals regardless of virus state (Bonferroni correction, $p<0.05$ ). Statistical analysis showed, that there is a trend for an interaction of virus group $X$ virus state on buried marbles $(F(1,20)=63.375, p=0.066)$. D1R 'OFF' animals buried significantly more marbles than subjects of their control group, dsRed 'OFF', and thus demonstrated an increased anxiety behavior (Bonferroni correction, $p<0.05$ ). Based on the behavioral results of Sonntag and Freund and their colleagues (Freund et al. 2016; Sonntag et al. 2014), we hypothesize that D1R 'ON' subjects demonstrate mania-like behavior whereas D1R 'OFF' animals show depression-like behavior. The a priori prediction was that a different anxiety behavior should be present only between D1R animals, therefore the one-sided tTest with Bonferroni correction was used. D1R 'OFF' subjects demonstrated an increased anxiety behavior indicated through significantly more buried marbles (Bonferroni correction, one-sided $\mathrm{p}<0.05$ ) (Fig. 3D).

\subsection{IL-6 IHC in the hippocampus}

A repeated measurements ANOVA were conducted to analyze the amount of IL-6-positive cells in 5 different regions of the hippocampus (hippocampal CA1, CA2, CA3, CA4 and DG) (Fig. 4). Analysis revealed a significant interaction of the virus group $X$ region $(F(4,17)=3.516, p=0.029)$, but not of virus 
group $X$ virus state $X$ region $(F(4,17)=0.722, p=0.58)$. In addition, the amount of IL-6-positive cells were dependent of the region $(F(4,17)=11.096, p<0.000)$. Due to the significant differences of IL-6-positive cells in subregions of the hippocampus, these regions were analyzed individually via MANOVA. Virus group had a significant effect on IL-6-positive cells in the CA3 region of the hippocampus $(F(1,20)=9.399$, $p=0.006$ ). The number of IL-6-positive cells are significantly increased in D1R 'OFF' compared to subjects transduced with dsRed (Bonferroni correction, $p<0.05$ ). A significant virus group $X$ virus state interaction revealed an influence of virus over-expression and its termination in the MPFC on IL-6-positive cells in the DG $(F(1,20)=5.12, p=0.035)$. However, differences between groups were not big enough to withstand Bonferroni correction (Bonferroni correction, $p>0.05$ ).

To determine if inflammation is changed due to differences of total cell numbers, DAPI-positive cells were analyzed via repeated measurements ANOVA and MANOVA. Neither region $X$ virus group $(F(4,17)=1.052$, $p=0.41)$, region $X$ virus state $(F(4,17)=1.501, p=0.25)$, nor virus group $X$ virus state $X$ region $(F(4,17)=$ $0.44, p=0.78$ ) had an influence on the amount of DAPI-positive cells.

\subsection{Correlation between IL-6 immunoreactivity and anxiety behavior}

To further analyze if IL- 6 as a marker for a pro-inflammatory state and anxiety behavior are connected, a correlation between IL-6-positive cells and buried marbles was performed (Fig. 5). Indeed, an increased number of IL-6-positive cells in the whole hippocampus is connected to an increased anxiety behavior indicated through more buried marbles $(r=0.461, p=0.023)$. Interestingly, IL-6-positive cells in the whole hippocampus is not associated with increased anxiety behavior measured as time spent in open arms in the EPM $(r=0.216, p=0.311)$ (Data not shown).

\section{Discussion}

Our results demonstrate an increased inflammatory state in the whole hippocampus following D1R overexpression and its termination in glutamatergic neurons of the mPFC. This increased inflammatory state is based on D1R manipulation, because over-expression of the control protein dsRed did not increase the number of IL-6-positive cells, indicating that increased inflammatory state is dependent of D1R manipulation.

D1R or dsRed manipulation of glutamatergic neurons had no effect on the total number of cells in the whole hippocampus. This unchanged number of cells indicates that increased IL- 6 represents increased inflammatory processes in the same neurons and our results are not based on a change of neuronal cell quantity.

Our results demonstrate an increased inflammatory state in D1R animals compared to dsRed subjects independent of their virus state. The PFC innervates via dopaminergic projections and thereby modulates multiple regions in the brain that are associated with depression, including the hippocampus. Our findings support the specific effect of D1R manipulation on the immune system within the hippocampus. 
But this effect is region specific, because differences are only present in the hippocampal CA3 and DG area. Hippocampal neurons are key contributor to anxiety and depression, because either inhibition of hippocampal inflammation (Zhou et al. 2018; Zhou et al. 2017) as well as stimulation of BDNF expression prevented depression-like behavior (Wang et al. 2016). Highlighting the key role of hippocampal functioning and mood.

D1R subjects in general, but especially D1R 'OFF' animals, show increased number of IL-6-positive cells in the hippocampal CA3 area, indicating an increased pro-inflammatory state. A similar effect was present in the DG, although the differences did not withstand the Bonferroni correction. Aberrant neuroinflammation creates severe consequences. For instance, IL-6 overproduction leads to neurodegeneration (Campbell et al. 1993; Fattori et al. 1995), and blocking of IL-6 signaling soften harmful IL-6 effects in the brain (Campbell et al. 2014). Although an IL-6 overproduction occurred in D1R 'OFF' subjects, no differences in total cell number, indicated through the number of DAPI-positive cells, were present. This result indicates, that aberrant immune activation was probably too short to induce neurodegeneration.

There is clear evidence suggesting that activation of the immune system may contribute to the etiology and manifestation of depression and anxiety (Capuron et al. 2004; Maes 1999; Miller et al. 2013; Vogelzangs et al. 2013; van West and Maes 1999). A well-stablished method to study consequences of innate immune system activation is the administration of LPS in rodents and humans. LPS treatment promotes an activation of immune-inflammatory pathways, accompanied by the release of proinflammatory cytokines, such as IL-6 in the brain and periphery (Bossù et al. 2012; Lacosta et al. 1999; Qin et al. 2007; Salazar et al. 2012; Sulakhiya et al. 2016; Sulakhiya et al. 2014). Behavioral consequences are increased anxiety and depression-like behavior (Anderson et al. 2015; Comim et al. 2010; Davis et al. 2017; Jangra et al. 2014; Salazar et al. 2012; Skurlova et al. 2011; Soncini et al. 2012; Sulakhiya et al. 2016; Tuon et al. 2008). Indicating an association between changes in mood following an aberrant activation of the immune system.

Our results demonstrate an increased inflammatory state in D1R animals compared to dsRed subjects. This chronic pro-inflammatory state can lead to behavioral abnormalities, such as aberrant anxiety behavior (Michopoulos et al. 2017). Interestingly, no effect of D1R manipulation in the mPFC of rats on anxiety measured by time spent in open arms in the EPM paradigm was present. However, open arm activity, latency until first entry and number of entries, seemed to be increased and therewith reflect antianxiety behavior (Walf and Frye 2007) in the D1R overexpressing group. In addition, D1R manipulation was able to influence anxiety behavior in the MB paradigm. Termination of D1R over-expression (D1R 'OFF') increased anxiety behavior in subjects compared to control (dsRed 'OFF') and D1R over-expression animals (D1R 'ON'). These results are in line with previous experiments with the same animal model, whereby D1R 'OFF' subjects revealed a depression-like phenotype (Freund et al. 2016). Anxiety and depression-like behavior were often accompanied by a pro-inflammatory state in the hippocampus (Liu et al. 2019b; Sulakhiya et al. 2016; Xu et al. 2016; Xu et al. 2015). Pharmacological treatment with agents reducing inflammation were able to alleviate both behavioral symptoms: depression-like behavior and 
anxiety (Liu et al. 2019b; Shal et al. 2019; Sulakhiya et al. 2016; Zager et al. 2018). Inhibiting IL-6 expression in the hippocampus plays a key role for the implementation of these beneficial effects (Shal et al. 2019; Skurlova et al. 2011; Sulakhiya et al. 2016). An additional potential mechanism of action is enhanced hippocampal neurogenesis (Liu et al. 2016). Also other manipulations can affect inflammation and induce anxiety and depression-like behavior in rodents, such as sleep deprivation (Wadhwa et al. 2018; Yin et al. 2017; Zielinski et al. 2014), chronic mild stress (Wang et al. 2018; You et al. 2011) and models for chronic inflammatory disease, like diabetes or metabolic syndrome (de Cossío et al. 2017; Dinel et al. 2011; Zhou et al. 2018). All those findings share, that increased inflammation in the hippocampus induces anxiety and depression-like behavior in rodents, and those behavioral symptoms could be attenuated through anti-inflammatory agents which reduced among other pro-inflammatory cytokines IL-6.

Here, we found an increased inflammatory state and anxiety behavior in D1R 'OFF' subjects. Our results are in line with previous in vitro findings, that the absence of D1R induced neuroinflammation (Yan et al. 2015). One potential mechanism of action of this animal model is a decreased endogenous expression of D1R following its viral over-expression. Termination of this over-expression leads to behavior which can be described as depression-like (Freund et al. 2016). A reduction of D1R could therefore be an explanation for increased inflammation within D1R 'OFF' subjects. There is a strong association of both chronic pro-inflammatory states in patients of BD (Muneer 2016; Stertz et al. 2013), MDD (Berk et al. 2013; Miller et al. 2009), anxiety (Miller et al. 2013; Pace and Heim 2011) and dopaminergic dysfunction (Berk et al. 2007). These findings are supported by the evidence, that adjunctive treatment with some antiinflammatory agents is able to alleviate manic and improve depressive symptoms (Ayorech et al. 2015; Goldsmith et al. 2016b; Köhler et al. 2014; Miller et al. 2017; Rosenblat 2019), whereas anti-inflammatory agents primarily improved motivation and anxiety in animal studies (Raison et al. 2013). Interestingly, many antidepressant drugs cause anti-inflammatory effects (Hannestad et al. 2011).

An increased anxiety behavior in D1R 'OFF' subjects match with these results. But even the analysis independent of treatment revealed a significant positive correlation of IL-6-positive cells in the whole hippocampus and anxiety behavior. The higher the pro-inflammatory state, the more marbles were buried, indicating the same association of inflammation and anxiety in our data. Indeed, antidepressants attenuate depression-like behavior and reduce pro-inflammatory cytokines within the hippocampus (Liu et al. 2017; Wang et al. 2015). Our data in combination with those findings further support this kind of manipulation as a potential animal model for BD. This is supported by the fact that depressive BD patients show anxiety related comorbidities (Goes 2015; Goldberg and Fawcett 2012; Vázquez et al. 2014) and increased anxiety behavior is one characteristic feature of animal models of depression (Beyer and Freund 2017; Wang et al. 2017). Indeed, increased pro-inflammatory cytokines resulted in a depression-like phenotype (Ma et al. 2017). Nonetheless, alterations of mPFC D1R are also present in BD patents, and indicate a role for D1R in BD symptoms (Gonul et al. 2009; Pantazopoulos et al. 2004; Suhara et al. 1992; Yao et al. 2013). According to the increased anxiety in D1R 'OFF' subjects is the trend, that these animals spent more time in the closed arm till they entered one of the open arms for the first time compared to D1R 'ON' and dsRed 'OFF' animals. This may indicate a decreased risk-taking and 
novelty-seeking behavior in D1R 'OFF' animals. Contrariwise, it means that D1R 'ON' subjects displayed an increased risk-taking behavior in comparison to the D1R 'OFF' group. This is in line with findings of decreased anxiety and increased risk-taking behavior following D1R virus over-expression (Sonntag et al. 2014) or optogenetic stimulation of mPFC D1R neurons (Hare et al. 2019). Zager and colleagues investigated Modafinil's role, a psychostimulant for treating narcolepsy, excessive daytime sleepiness, sleep apnea and shift work, on LPS-induced neuroinflammation. Modafinil was able to prevent LPSinduced anxiety and depression-like behavior and inflammation. Interestingly, D1R signaling was necessary for Modafinil's mechanism of action on locomotion and anxiety (Zager et al. 2018). Further supporting a direct link of the D1R and the immune system.

One limitation of this study is the usage of DOX. It should be taken into account that inflammatory state indicated through IL-6-positive cells should be considered higher in 'ON' subjects, especially in the D1R 'ON' group. This estimation is based on the fact, that these subjects were treated with DOX, an antibiotic, that decreases inflammatory processes and thereby IL-6 production and signaling (Di Caprio et al. 2015; Ikeda-Dantsuji et al. 2007; Kucuk et al. 2009).

To sum up, D1R stimulation in the mPFC results in mania-like behavior (Freund et al. 2016; Hare et al. 2019; Sonntag et al. 2014) and termination of previous viral over-expression in depression-like behavior (Freund et al. 2016). D1R over-expression in the mPFC resulted in decreased D2R expression (Sonntag et al. 2014) and its termination induced an increased expression of cyclic AMP-responsive element binding protein (CREB) in the nucleus accumbens (Freund et al. 2016). Both findings support the behavioral results on a molecular level, because decreased D2R in the nucleus accumbens is linked to impulsive behavior (Dalley et al. 2007; Volkow et al. 1993) and increased CREB in the nucleus accumbens is associated with depression-like behavior (Barrot et al. 2002; Pliakas et al. 2001). Here, we demonstrated a link between D1R manipulation, increased inflammation in the brain and anxiety.

\section{Conclusions}

This study shows, that D1R over-expression within the rats' mPFC neither significantly affect anxiety behavior nor inflammation in the brain. Interestingly, termination of viral D1R over-expression alone was sufficient enough to induce increased anxiety and inflammation in the hippocampus. Thereby providing a connection between D1R manipulation, increased inflammational state in the brain and anxiety. We hypothesize, that D1R over-expression induces a pro-inflammatory state which is kept at low level due to administration of DOX. Termination of DOX enhances inflammatory processes and induce behavioral abnormalities resembling depression-like behavior. Therefore, this chronic inflammation may lead to a BD-like phenotype in combination with DOX's properties of inhibiting inflammation. The behavioral findings in combination with molecular results strengthens the described animal model as a very promising animal model for BD (Beyer and Freund 2017).

\section{Abbreviations}




$\begin{array}{ll}\text { BD } & \text { bipolar disorder } \\ \text { BDNF } & \text { brain-derived neurotrophic factor } \\ \text { CaMKII } & \text { calmodulin Kinase II } \\ \text { CREB } & \text { cyclic AMP-responsive element binding protein } \\ \text { DA } & \text { dopamine } \\ \text { DAPI } & \text { 4',6-diamidino-2-phenylindole } \\ \text { DG } & \text { dentate gyrus } \\ \text { DOX } & \text { doxycycline } \\ \text { D1R } & \text { dopamine D1 Receptor } \\ \text { EPM } & \text { elevated plus maze } \\ \text { IHC } & \text { Immunohistochemistry } \\ \text { IL-6 } & \text { interleukin-6 } \\ \text { LPS } & \text { lipopolysaccharide }\end{array}$

MANOVA multivariate analysis of variance

MDD major depression disorder

MPFC medial PFC

NLRP3 nucleotide-binding oligomerization domain-like receptor pyrin domain-containing 3

Tet.On Tetracycline-On inducible lentiviral vector system

\section{Declarations}

\section{Ethics approval and consent to participate:}

All experiments were carried out in agreement with the principles regarding the care and use of animals adopted by the German Animal Welfare Law for the prevention of cruelty to animals after approval by the LANUV (Landesamt für Natur, Umwelt und Verbraucherschutz Northrhine-Westfalia).

\section{Consent for publication:}

Not applicable 


\section{Availability of data and materials:}

Data is made available upon request.

\section{Competing interests:}

None of the authors have any financial and non-financial competing interests.

\section{Funding:}

The authors acknowledge the support the doctoral scholarship of the German Academic Scholarship Foundation to DKEB.

\section{Author's contributions:}

NF and DKEB both designed the study. DKEB carried out all behavioral experiments, analyzed behavior and wrote the first draft manuscript. Immunohistochemical experiments and cell counting was performed by AM. NF promoted DKEB in statistical analysis, interpretation of data and contributed with proof reading and refining the manuscript. All authors approved the final manuscript.

\section{Acknowledgements:}

The authors want to thank Dr. Kai-Christian Sonntag, McLean Hospital, HMS, for providing the TetOn lentivirus system and the team around Dr. Thorsten Trimbuch of the Viral Core Facility, Charité Universitätsmedizin Berlin, for virus production.

\section{References}

Anderson ST, Commins S, Moynagh PN, Coogan AN. Lipopolysaccharide-induced sepsis induces longlasting affective changes in the mouse. Brain. Behav. Immun. 2015 Jan;43:98-109.

Ayorech Z, Tracy DK, Baumeister D, Giaroli G. Taking the fuel out of the fire: evidence for the use of antiinflammatory agents in the treatment of bipolar disorders. J. Affect. Disord. 2015 Mar 15;174:467-78.

Barrot M, Olivier JDA, Perrotti LI, DiLeone RJ, Berton O, Eisch AJ, et al. CREB activity in the nucleus accumbens shell controls gating of behavioral responses to emotional stimuli. Proc. Natl. Acad. Sci. U. S. A. 2002 Aug 20;99(17):11435-40.

Benedetti F, Poletti S, Hoogenboezem TA, Locatelli C, de Wit H, Wijkhuijs AJM, et al. Higher Baseline Proinflammatory Cytokines Mark Poor Antidepressant Response in Bipolar Disorder. J. Clin. Psychiatry. 2017 Oct;78(8):e986-93.

Berk M, Dodd S, Kauer-Sant'Anna M, Malhi GS, Bourin M, Kapczinski F, et al. Dopamine dysregulation syndrome: implications for a dopamine hypothesis of bipolar disorder. Acta Psychiatr. Scand. 2007 Oct 1;116:41-9. 
Berk M, Williams LJ, Jacka FN, O’Neil A, Pasco JA, Moylan S, et al. So depression is an inflammatory disease, but where does the inflammation come from? BMC Med. 2013 Sep 12;11(1):200.

Beyer DKE, Freund N. Animal models for bipolar disorder: from bedside to the cage. Int. J. Bipolar Disord. 2017 Oct 13;5:35.

Bossù $P$, Cutuli D, Palladino I, Caporali $P$, Angelucci $F$, Laricchiuta $D$, et al. A single intraperitoneal injection of endotoxin in rats induces long-lasting modifications in behavior and brain protein levels of TNF- $a$ and IL-18. J. Neuroinflammation. 2012 May 29;9(1):101.

Boufidou F, Nikolaou C, Alevizos B, Liappas IA, Christodoulou GN. Cytokine production in bipolar affective disorder patients under lithium treatment. J. Affect. Disord. 2004 Oct 15;82(2):309-13.

Brietzke E, Kauer-Sant'anna M, Teixeira AL, Kapczinski F. Abnormalities in serum chemokine levels in euthymic patients with bipolar disorder. Brain. Behav. Immun. 2009a Nov;23(8):1079-82.

Brietzke E, Stertz L, Fernandes BS, Kauer-Sant'Anna M, Mascarenhas M, Escosteguy Vargas A, et al. Comparison of cytokine levels in depressed, manic and euthymic patients with bipolar disorder. J. Affect. Disord. 2009b Aug;116(3):214-7.

Campbell IL, Abraham CR, Masliah E, Kemper P, Inglis JD, Oldstone MB, et al. Neurologic disease induced in transgenic mice by cerebral overexpression of interleukin 6. Proc. Natl. Acad. Sci. 1993 Nov 1;90(21):10061-5.

Campbell IL, Erta M, Lim SL, Frausto R, May U, Rose-John S, et al. Trans-Signaling Is a Dominant Mechanism for the Pathogenic Actions of Interleukin-6 in the Brain. J. Neurosci. 2014 Feb 12;34(7):250313.

Capuron L, Pagnoni G, Demetrashvili MF, Lawson DH, Fornwalt FB, Woolwine B, et al. Basal ganglia hypermetabolism and symptoms of fatigue during interferon-alpha therapy. Neuropsychopharmacol. Off. Publ. Am. Coll. Neuropsychopharmacol. 2007 Nov;32(11):2384-92.

Capuron L, Pagnoni G, Drake DF, Woolwine BJ, Spivey JR, Crowe RJ, et al. Dopaminergic mechanisms of reduced basal ganglia responses to hedonic reward during interferon alfa administration. Arch. Gen. Psychiatry. 2012 Oct;69(10):1044-53.

Capuron L, Ravaud A, Miller AH, Dantzer R. Baseline mood and psychosocial characteristics of patients developing depressive symptoms during interleukin-2 and/or interferon-alpha cancer therapy. Brain. Behav. Immun. 2004 May;18(3):205-13.

Comim CM, Cassol-Jr OJ, Constantino LC, Petronilho F, Constantino LS, Stertz L, et al. Depressive-Like Parameters in Sepsis Survivor Rats. Neurotox. Res. 2010 Apr 1;17(3):279-86. 
de Cossío LF, Fourrier C, Sauvant J, Everard A, Capuron L, Cani PD, et al. Impact of prebiotics on metabolic and behavioral alterations in a mouse model of metabolic syndrome. Brain. Behav. Immun. 2017 Aug;64:33-49.

Dalley JW, Fryer TD, Brichard L, Robinson ESJ, Theobald DEH, Lääne K, et al. Nucleus accumbens D2/3 receptors predict trait impulsivity and cocaine reinforcement. Science. 2007 Mar 2;315(5816):1267-70.

Davis RL, Stevens CW, Thomas Curtis J. The opioid antagonist, $\beta$-funaltrexamine, inhibits lipopolysaccharide-induced neuroinflammation and reduces sickness behavior in mice. Physiol. Behav. 2017 01;173:52-60.

Di Caprio R, Lembo S, Di Costanzo L, Balato A, Monfrecola G. Anti-Inflammatory Properties of Low and High Doxycycline Doses: An In Vitro Study [Internet]. Mediators Inflamm. 2015 [cited 2019 Dec 4]. Available from: https://www.hindawi.com/journals/mi/2015/329418/

Dinel A-L, André C, Aubert A, Ferreira G, Layé S, Castanon N. Cognitive and emotional alterations are related to hippocampal inflammation in a mouse model of metabolic syndrome. PloS One. 2011;6(9):e24325.

DiSabato D, Quan N, Godbout JP. Neuroinflammation: The Devil is in the Details. J. Neurochem. 2016 Oct;139(Suppl 2):136-53.

D'Mello C, Ronaghan N, Zaheer R, Dicay M, Le T, MacNaughton WK, et al. Probiotics Improve Inflammation-Associated Sickness Behavior by Altering Communication between the Peripheral Immune System and the Brain. J. Neurosci. Off. J. Soc. Neurosci. 2015 Jul 29;35(30):10821-30.

Eisenberger NI, Berkman ET, Inagaki TK, Rameson LT, Mashal NM, Irwin MR. Inflammation-induced anhedonia: endotoxin reduces ventral striatum responses to reward. Biol. Psychiatry. 2010 Oct 15;68(8):748-54.

van Enkhuizen J, Geyer MA, Minassian A, Perry W, Henry BL, Young JW. Investigating the underlying mechanisms of aberrant behaviors in bipolar disorder from patients to models: Rodent and human studies. Neurosci. Biobehav. Rev. 2015 Nov;58:4-18.

Fattori E, Lazzaro D, Musiani P, Modesti A, Alonzi T, Ciliberto G. IL-6 Expression in Neurons of Transgenic Mice Causes Reactive Astrocytosis and Increase in Ramified Microglial Cells but no Neuronal Damage. Eur. J. Neurosci. 1995;7(12):2441-9.

Felger JC. Imaging the Role of Inflammation in Mood and Anxiety-related Disorders. Curr. Neuropharmacol. 2018;16(5):533-58.

Filippi M, Bar-Or A, Piehl F, Preziosa P, Solari A, Vukusic S, et al. Multiple sclerosis. Nat. Rev. Dis. Primer. 2018 08;4(1):43. 
Fischer CW, Eskelund A, Budac DP, Tillmann S, Liebenberg N, Elfving B, et al. Interferon-alpha treatment induces depression-like behaviour accompanied by elevated hippocampal quinolinic acid levels in rats. Behav. Brain Res. 2015 Oct 15;293:166-72.

Freund N, Thompson BS, Sonntag K, Meda S, Andersen SL. When the party is over: depressive-like states in rats following termination of cortical D1 receptor overexpression. Psychopharmacology (Berl.). 2016 Apr;233(7):1191-201.

Fu X, Zunich SM, O'Connor JC, Kavelaars A, Dantzer R, Kelley KW. Central Administration of Lipopolysaccharide Induces Depressive-like Behavior in Vivo and Activates Brain Indoleamine 2,3 Dioxygenase In Murine Organotypic Hippocampal Slice Cultures. J. Neuroinflammation. 2010 Aug 2;7(1):43.

Gage GJ, Kipke DR, Shain W. Whole animal perfusion fixation for rodents. J. Vis. Exp. JoVE. 2012 Jul 30; (65).

Goes FS. The importance of anxiety states in bipolar disorder. Curr. Psychiatry Rep. 2015 Feb;17(2):3.

Goldberg D, Fawcett J. The importance of anxiety in both major depression and bipolar disorder. Depress. Anxiety. 2012 Jun;29(6):471-8.

Goldsmith DR, Haroon E, Woolwine BJ, Jung MY, Wommack EC, Harvey PD, et al. Inflammatory markers are associated with decreased psychomotor speed in patients with major depressive disorder. Brain. Behav. Immun. 2016a Aug;56:281-8.

Goldsmith DR, Rapaport MH, Miller BJ. A meta-analysis of blood cytokine network alterations in psychiatric patients: comparisons between schizophrenia, bipolar disorder and depression. Mol. Psychiatry. 2016b;21(12):1696-709.

Goldstein BI, Kemp DE, Soczynska JK, Mclntyre RS. Inflammation and the phenomenology, pathophysiology, comorbidity, and treatment of bipolar disorder: a systematic review of the literature. J. Clin. Psychiatry. 2009 Aug;70(8):1078-90.

Gonul AS, Coburn K, Kula M. Cerebral blood flow, metabolic, receptor, and transporter changes in bipolar disorder: the role of PET and SPECT studies. Int. Rev. Psychiatry Abingdon Engl. 2009;21(4):323-35.

Gründer G, Cumming P. Chapter 7 - The Dopamine Hypothesis of Schizophrenia: Current Status. In: Abel T, Nickl-Jockschat T, editors. Neurobiol. Schizophr. [Internet]. San Diego: Academic Press; 2016 [cited 2019 Nov 27]. p. 109-24. Available from:

http://www.sciencedirect.com/science/article/pii/B978012801829300015X

Guloksuz S, Altinbas K, Aktas Cetin E, Kenis G, Bilgic Gazioglu S, Deniz G, et al. Evidence for an association between tumor necrosis factor-alpha levels and lithium response. J. Affect. Disord. 2012 Dec 20;143(1):148-52. 
Han X, Li B, Ye X, Mulatibieke T, Wu J, Dai J, et al. Dopamine D2 receptor signalling controls inflammation in acute pancreatitis via a PP2A-dependent Akt/NF-kB signalling pathway. Br. J. Pharmacol. 2017 Dec;174(24):4751-70.

Hannestad J, DellaGioia N, Bloch M. The effect of antidepressant medication treatment on serum levels of inflammatory cytokines: a meta-analysis. Neuropsychopharmacol. Off. Publ. Am. Coll. Neuropsychopharmacol. 2011 Nov;36(12):2452-9.

Hare BD, Shinohara R, Liu RJ, Pothula S, DiLeone RJ, Duman RS. Optogenetic stimulation of medial prefrontal cortex Drd1 neurons produces rapid and long-lasting antidepressant effects. Nat. Commun. [Internet]. 2019 Jan 15 [cited 2019 Jan 24];10. Available from: https://www.ncbi.nlm.nih.gov/pmc/articles/PMC6333924/

Haroon E, Raison CL, Miller AH. Psychoneuroimmunology meets neuropsychopharmacology: translational implications of the impact of inflammation on behavior. Neuropsychopharmacol. Off. Publ. Am. Coll. Neuropsychopharmacol. 2012 Jan;37(1):137-62.

Ikeda-Dantsuji Y, Konomi I, Nagayama A. Effects of levofloxacin and doxycycline on interleukin-6 production of Chlamydia trachomatis-infected human synovial fibroblasts. Chemotherapy. 2007;53(5):332-7.

Jangra A, Lukhi MM, Sulakhiya K, Baruah CC, Lahkar M. Protective effect of mangiferin against lipopolysaccharide-induced depressive and anxiety-like behaviour in mice. Eur. J. Pharmacol. 2014 Oct 5;740:337-45.

Kamata M, Higuchi H, Yoshimoto M, Yoshida K, Shimizu T. Effect of single intracerebroventricular injection of alpha-interferon on monoamine concentrations in the rat brain. Eur. Neuropsychopharmacol. J. Eur. Coll. Neuropsychopharmacol. 2000 Mar;10(2):129-32.

Kaster MP, Gadotti VM, Calixto JB, Santos ARS, Rodrigues ALS. Depressive-like behavior induced by tumor necrosis factor-a in mice. Neuropharmacology. 2012 Jan 1;62(1):419-26.

Kato T, Kubota M, Kasahara T. Animal models of bipolar disorder. Neurosci. Biobehav. Rev. 2007;31(6):832-42.

Kitagami T, Yamada K, Miura H, Hashimoto R, Nabeshima T, Ohta T. Mechanism of systemically injected interferon-alpha impeding monoamine biosynthesis in rats: role of nitric oxide as a signal crossing the blood-brain barrier. Brain Res. 2003 Jul 18;978(1-2):104-14.

Knijff EM, Breunis MN, Kupka RW, de Wit HJ, Ruwhof C, Akkerhuis GW, et al. An imbalance in the production of IL- 1 beta and IL- 6 by monocytes of bipolar patients: restoration by lithium treatment. Bipolar Disord. 2007 Nov;9(7):743-53. 
Köhler O, Benros ME, Nordentoft M, Farkouh ME, lyengar RL, Mors O, et al. Effect of anti-inflammatory treatment on depression, depressive symptoms, and adverse effects: a systematic review and metaanalysis of randomized clinical trials. JAMA Psychiatry. 2014 Dec 1;71(12):1381-91.

Kucuk A, Kabadere S, Tosun M, Koken T, Kinaci MK, Isikli B, et al. Protective effects of doxycycline in ischemia/reperfusion injury on kidney. J. Physiol. Biochem. 2009 Jun;65(2):183-91.

Lacosta S, Merali Z, Anisman H. Behavioral and neurochemical consequences of lipopolysaccharide in mice: anxiogenic-like effects. Brain Res. 1999 Feb 13;818(2):291-303.

Leonard BE. Impact of inflammation on neurotransmitter changes in major depression: An insight into the action of antidepressants. Prog. Neuropsychopharmacol. Biol. Psychiatry. 2014 Jan 3;48:261-7.

Liu L, Zhang L, Wang T, Chen L. Dopamine D1 receptor in the medial prefrontal cortex mediates anxietylike behaviors induced by blocking glutamatergic activity of the ventral hippocampus in rats. Brain Res. 2019a 01;1704:59-67.

Liu L, Zhang Q, Cai Y, Sun D, He X, Wang L, et al. Resveratrol counteracts lipopolysaccharide-induced depressive-like behaviors via enhanced hippocampal neurogenesis. Oncotarget. 2016 Aug 30;7(35):56045-59.

Liu T, Ma Y, Zhang R, Zhong H, Wang L, Zhao J, et al. Resveratrol ameliorates estrogen deficiency-induced depression- and anxiety-like behaviors and hippocampal inflammation in mice. Psychopharmacology (Berl.). 2019b Apr;236(4):1385-99.

Liu Y-M, Niu L, Wang L-L, Bai L, Fang X-Y, Li Y-C, et al. Berberine attenuates depressive-like behaviors by suppressing neuro-inflammation in stressed mice. Brain Res. Bull. 2017 Sep;134:220-7.

Lochhead JJ, Ronaldson PT, Davis TP. Hypoxic Stress and Inflammatory Pain Disrupt Blood-Brain Barrier Tight Junctions: Implications for Drug Delivery to the Central Nervous System. AAPS J. 2017 Jul;19(4):910-20.

Logan RW, McClung CA. Animal models of bipolar mania: The past, present and future. Neuroscience. 2016 May 3;321:163-88.

Lu Y-R, Rao Y-B, Mou Y-J, Chen Y, Lou H-F, Zhang Y, et al. High concentrations of serum interleukin-6 and interleukin-8 in patients with bipolar disorder. Medicine (Baltimore). 2019 Feb;98(7):e14419.

Ma L, Demin KA, Kolesnikova TO, Kharsko SL, Zhu X, Yuan X, et al. Animal inflammation-based models of depression and their application to drug discovery. Expert Opin. Drug Discov. 2017 Oct 3;12(10):9951009.

Maes M. Major depression and activation of the inflammatory response system. Adv. Exp. Med. Biol. 1999;461:25-46. 
Majer M, Welberg LAM, Capuron L, Pagnoni G, Raison CL, Miller AH. IFN-alpha-induced motor slowing is associated with increased depression and fatigue in patients with chronic hepatitis C. Brain. Behav. Immun. 2008 Aug;22(6):870-80.

Makino M, Kitano Y, Komiyama C, Takasuna K. Human interferon-a increases immobility in the forced swimming test in rats. Psychopharmacology (Berl.). 2000 Jan 1;148(1):106-10.

Michopoulos V, Powers A, Gillespie CF, Ressler KJ, Jovanovic T. Inflammation in Fear- and Anxiety-Based Disorders: PTSD, GAD, and Beyond. Neuropsychopharmacology. 2017 Jan;42(1):254-70.

Miller AH, Haroon E, Felger JC. Therapeutic Implications of Brain-Immune Interactions: Treatment in Translation. Neuropsychopharmacol. Off. Publ. Am. Coll. Neuropsychopharmacol. 2017;42(1):334-59.

Miller AH, Haroon E, Raison CL, Felger JC. Cytokine targets in the brain: impact on neurotransmitters and neurocircuits. Depress. Anxiety. 2013 Apr;30(4):297-306.

Miller AH, Maletic V, Raison CL. Inflammation and Its Discontents: The Role of Cytokines in the Pathophysiology of Major Depression. Biol. Psychiatry. 2009 May 1;65(9):732-41.

Modabbernia A, Taslimi S, Brietzke E, Ashrafi M. Cytokine alterations in bipolar disorder: a meta-analysis of 30 studies. Biol. Psychiatry. 2013 Jul 1;74(1):15-25.

Muneer A. Bipolar Disorder: Role of Inflammation and the Development of Disease Biomarkers. Psychiatry Investig. 2016 Jan;13(1):18-33.

Na K-S, Jung H-Y, Kim Y-K. The role of pro-inflammatory cytokines in the neuroinflammation and neurogenesis of schizophrenia. Prog. Neuropsychopharmacol. Biol. Psychiatry. 2014 Jan 3;48:277-86.

Neurath MF, Finotto S. IL-6 signaling in autoimmunity, chronic inflammation and inflammationassociated cancer. Cytokine Growth Factor Rev. 2011 Apr 1;22(2):83-9.

Nutt DJ. Relationship of neurotransmitters to the symptoms of major depressive disorder. J. Clin. Psychiatry. 2008;69 Suppl E1:4-7.

Onufriev MV, Freiman SV, Peregud DI, Kudryashova IV, Tishkina AO, Stepanichev MYu, et al. Neonatal proinflammatory stress induces accumulation of corticosterone and interleukin- 6 in the hippocampus of juvenile rats: Potential mechanism of synaptic plasticity impairments. Biochem. Mosc. 2017 Mar $1 ; 82(3): 275-81$.

Ortiz-Domínguez A, Hernández ME, Berlanga C, Gutiérrez-Mora D, Moreno J, Heinze G, et al. Immune variations in bipolar disorder: phasic differences. Bipolar Disord. 2007 Sep;9(6):596-602.

Pace TWW, Heim CM. A short review on the psychoneuroimmunology of posttraumatic stress disorder: from risk factors to medical comorbidities. Brain. Behav. Immun. 2011 Jan;25(1):6-13. 
Pantazopoulos H, Stone D, Walsh J, Benes FM. Differences in the cellular distribution of D1 receptor mRNA in the hippocampus of bipolars and schizophrenics. Synap. N. Y. N. 2004 Dec 1;54(3):147-55.

Paxinos G, Watson CR, Emson PC. AChE-stained horizontal sections of the rat brain in stereotaxic coordinates. J. Neurosci. Methods. 1980 Dec;3(2):129-49.

Pliakas AM, Carlson RR, Neve RL, Konradi C, Nestler EJ, Carlezon WA. Altered responsiveness to cocaine and increased immobility in the forced swim test associated with elevated cAMP response elementbinding protein expression in nucleus accumbens. J. Neurosci. Off. J. Soc. Neurosci. 2001 Sep 15;21(18):7397-403.

Qin L, Wu X, Block ML, Liu Y, Breese GR, Hong J-S, et al. Systemic LPS causes chronic neuroinflammation and progressive neurodegeneration. Glia. 2007;55(5):453-62.

Raison CL, Miller AH. The evolutionary significance of depression in Pathogen Host Defense (PATHOS-D). Mol. Psychiatry. 2013 Jan;18(1):15-37.

Raison CL, Rutherford RE, Woolwine BJ, Shuo C, Schettler P, Drake DF, et al. A randomized controlled trial of the tumor necrosis factor antagonist infliximab for treatment-resistant depression: the role of baseline inflammatory biomarkers. JAMA Psychiatry. 2013 Jan;70(1):31-41.

Reichenberg A, Yirmiya R, Schuld A, Kraus T, Haack M, Morag A, et al. Cytokine-associated emotional and cognitive disturbances in humans. Arch. Gen. Psychiatry. 2001 May;58(5):445-52.

Remus JL, Dantzer R. Inflammation Models of Depression in Rodents: Relevance to Psychotropic Drug Discovery. Int. J. Neuropsychopharmacol. [Internet]. 2016 Sep 1 [cited 2017 May 23];19(9). Available from: https://academic.oup.com/ijnp/article/19/9/pyw028/2488254/Inflammation-Models-of-

Depression-in-Rodents

Riazi K, Galic MA, Kentner AC, Reid AY, Sharkey KA, Pittman QJ. Microglia-dependent alteration of glutamatergic synaptic transmission and plasticity in the hippocampus during peripheral inflammation. J. Neurosci. Off. J. Soc. Neurosci. 2015 Mar 25;35(12):4942-52.

Rosenblat JD. Targeting the immune system in the treatment of bipolar disorder. Psychopharmacology (Berl.) [Internet]. 2019 Feb 13 [cited 2019 Sep 16]; Available from: https://doi.org/10.1007/s00213-019$5175-x$

Salazar A, Gonzalez-Rivera BL, Redus L, Parrott JM, O'Connor JC. Indoleamine 2,3-dioxygenase mediates anhedonia and anxiety-like behaviors caused by peripheral lipopolysaccharide immune challenge. Horm. Behav. 2012 Aug 1;62(3):202-9.

Sarkar C, Basu B, Chakroborty D, Dasgupta PS, Basu S. The immunoregulatory role of dopamine: an update. Brain. Behav. Immun. 2010 May;24(4):525-8. 
Schain M, KreisI WC. Neuroinflammation in Neurodegenerative Disorders-a Review. Curr. Neurol. Neurosci. Rep. 2017;17(3):25.

Schindelin J, Arganda-Carreras I, Frise E, Kaynig V, Longair M, Pietzsch T, et al. Fiji: an open-source platform for biological-image analysis. Nat. Methods. 2012 Jul;9(7):676-82.

Shal B, Khan A, Naveed M, Ullah Khan N, Ihsan-Ul-Haq null, D AlSharari S, et al. Effect of 25-methoxy hispidol $\mathrm{A}$ isolated from Poncirus trifoliate against bacteria-induced anxiety and depression by targeting neuroinflammation, oxidative stress and apoptosis in mice. Biomed. Pharmacother. Biomedecine Pharmacother. 2019 Mar;111:209-23.

Sharma AN, Fries GR, Galvez JF, Valvassori SS, Soares JC, Carvalho AF, et al. Modeling mania in preclinical settings: A comprehensive review. Prog. Neuropsychopharmacol. Biol. Psychiatry. 2016 Apr 3;66:22-34.

Shuto H, Kataoka Y, Horikawa T, Fujihara N, Oishi R. Repeated interferon-alpha administration inhibits dopaminergic neural activity in the mouse brain. Brain Res. 1997 Feb 7;747(2):348-51.

Simen BB, Duman CH, Simen AA, Duman RS. TNFalpha signaling in depression and anxiety: behavioral consequences of individual receptor targeting. Biol. Psychiatry. 2006 May 1;59(9):775-85.

Skurlova M, Stofkova A, Jurcovicova J. Anxiety-like behavior in the elevated-plus maze tests and enhanced IL-1 $\beta$, IL-6, NADPH oxidase-1, and iNOS mRNAs in the hippocampus during early stage of adjuvant arthritis in rats. Neurosci. Lett. 2011 Jan 7;487(2):250-4.

Soncini R, de Souza DF, Neves AP, Braga DS, Andrade CAF, Giusti-Paiva A. Dipyrone attenuates acute sickness response to lipopolysaccharide in mice. Neurosci. Lett. 2012 May 10;516(1):114-8.

Sonntag KC, Brenhouse HC, Freund N, Thompson BS, Puhl M, Andersen SL. Viral over-expression of D1 dopamine receptors in the prefrontal cortex increase high-risk behaviors in adults: comparison with adolescents. Psychopharmacology (Berl.). 2014 Apr;231(8):1615-26.

Stertz L, Magalhães PVS, Kapczinski F. Is bipolar disorder an inflammatory condition? The relevance of microglial activation. Curr. Opin. Psychiatry. 2013 Jan;26(1):19-26.

Stewart SA, Dykxhoorn DM, Palliser D, Mizuno H, Yu EY, An DS, et al. Lentivirus-delivered stable gene silencing by RNAi in primary cells. RNA N. Y. N. 2003 Apr;9(4):493-501.

Suhara T, Nakayama K, Inoue O, Fukuda H, Shimizu M, Mori A, et al. D1 dopamine receptor binding in mood disorders measured by positron emission tomography. Psychopharmacology (Berl.). 1992 Jan 1;106(1):14-8.

Sulakhiya K, Keshavlal GP, Bezbaruah BB, Dwivedi S, Gurjar SS, Munde N, et al. Lipopolysaccharide induced anxiety- and depressive-like behaviour in mice are prevented by chronic pre-treatment of 
esculetin. Neurosci. Lett. 2016 Jan 12;611:106-11.

Sulakhiya K, Kumar P, Jangra A, Dwivedi S, Hazarika NK, Baruah CC, et al. Honokiol abrogates lipopolysaccharide-induced depressive like behavior by impeding neuroinflammation and oxidonitrosative stress in mice. Eur. J. Pharmacol. 2014 Dec 5;744:124-31.

Tsai S-YM, Yang Y-Y, Kuo C-J, Chen C-C, Leu S-JC. Effects of symptomatic severity on elevation of plasma soluble interleukin-2 receptor in bipolar mania. J. Affect. Disord. 2001 May 1;64(2):185-93.

Tuon L, Comim CM, Petronilho F, Barichello T, Izquierdo I, Quevedo J, et al. Time-dependent behavioral recovery after sepsis in rats. Intensive Care Med. 2008 Sep 1;34(9):1724-31.

Valvassori SS, Tonin PT, Varela RB, Carvalho AF, Mariot E, Amboni RT, et al. Lithium modulates the production of peripheral and cerebral cytokines in an animal model of mania induced by dextroamphetamine. Bipolar Disord. 2015 Aug;17(5):507-17.

Vázquez GH, Baldessarini RJ, Tondo L. Co-occurrence of anxiety and bipolar disorders: clinical and therapeutic overview. Depress. Anxiety. 2014 Mar;31(3):196-206.

Vogelzangs N, Beekman ATF, de Jonge P, Penninx BWJH. Anxiety disorders and inflammation in a large adult cohort. Transl. Psychiatry. 2013 Apr;3(4):e249.

Volkow ND, Fowler JS, Wang G-J, Hitzemann R, Logan J, Schlyer DJ, et al. Decreased dopamine D2 receptor availability is associated with reduced frontal metabolism in cocaine abusers. Synapse. 1993;14(2):169-77.

Wachholz S, Knorr A, Mengert L, Plümper J, Sommer R, Juckel G, et al. Interleukin-4 is a participant in the regulation of depressive-like behavior. Behav. Brain Res. 2017 May 30;326:165-72.

Wadhwa M, Chauhan G, Roy K, Sahu S, Deep S, Jain V, et al. Caffeine and Modafinil Ameliorate the Neuroinflammation and Anxious Behavior in Rats during Sleep Deprivation by Inhibiting the Microglia Activation. Front. Cell. Neurosci. 2018;12:49.

Walf AA, Frye CA. The use of the elevated plus maze as an assay of anxiety-related behavior in rodents. Nat. Protoc. 2007 Feb;2(2):322-8.

Wang J, Duan P, Cui Y, Li Q, Shi Y. Geniposide alleviates depression-like behavior via enhancing BDNF expression in hippocampus of streptozotocin-evoked mice. Metab. Brain Dis. 2016 Oct 1;31(5):1113-22.

Wang N, Yu H-Y, Shen X-F, Gao Z-Q, Yang C, Yang J-J, et al. The rapid antidepressant effect of ketamine in rats is associated with down-regulation of pro-inflammatory cytokines in the hippocampus. Ups. J. Med. Sci. 2015;120(4):241-8. 
Wang Q, Timberlake MA, Prall K, Dwivedi Y. The recent progress in animal models of depression. Prog. Neuropsychopharmacol. Biol. Psychiatry. 2017 Apr 8;77:99-109.

Wang Y-L, Han Q-Q, Gong W-Q, Pan D-H, Wang L-Z, Hu W, et al. Microglial activation mediates chronic mild stress-induced depressive- and anxiety-like behavior in adult rats. J. Neuroinflammation. 2018 Jan $17 ; 15(1): 21$.

van West D, Maes M. Activation of the inflammatory response system: A new look at the etiopathogenesis of major depression. Neuro Endocrinol. Lett. 1999;20(1-2):11-7.

Xia Q-P, Cheng Z-Y, He L. The modulatory role of dopamine receptors in brain neuroinflammation. Int. Immunopharmacol. 2019 Nov;76:105908.

Xing B, Guo J, Meng X, Wei S, Li S. The dopamine D1 but not D3 receptor plays a fundamental role in spatial working memory and BDNF expression in prefrontal cortex of mice. Behav. Brain Res. 2012 Nov $1 ; 235(1): 36-41$.

Xu Y, Sheng H, Bao Q, Wang Y, Lu J, Ni X. NLRP3 inflammasome activation mediates estrogen deficiencyinduced depression- and anxiety-like behavior and hippocampal inflammation in mice. Brain. Behav. Immun. 2016 Aug 1;56:175-86.

Xu Y, Sheng H, Tang Z, Lu J, Ni X. Inflammation and increased IDO in hippocampus contribute to depression-like behavior induced by estrogen deficiency. Behav. Brain Res. 2015 Jul 15;288:71-8.

Yan Y, Jiang W, Liu L, Wang X, Ding C, Tian Z, et al. Dopamine controls systemic inflammation through inhibition of NLRP3 inflammasome. Cell. 2015 Jan 15;160(1-2):62-73.

Yao J, Pan Y, Ding M, Pang H, Wang B. Meta-analysis shows dopamine receptor D1 gene polymorphism is associated with bipolar disorder but not with schizophrenia. Psychiatry Res. 2013 Dec 30;210(3):13245.

Yin M, Chen Y, Zheng H, Pu T, Marshall C, Wu T, et al. Assessment of mouse cognitive and anxiety-like behaviors and hippocampal inflammation following a repeated and intermittent paradoxical sleep deprivation procedure. Behav. Brain Res. 2017 15;321:69-78.

You Z, Luo C, Zhang W, Chen Y, He J, Zhao Q, et al. Pro- and anti-inflammatory cytokines expression in rat's brain and spleen exposed to chronic mild stress: involvement in depression. Behav. Brain Res. 2011 Nov 20;225(1):135-41.

Zager A, Brandão WN, Margatho RO, Peron JP, Tufik S, Andersen ML, et al. The wake-promoting drug Modafinil prevents motor impairment in sickness behavior induced by LPS in mice: Role for dopaminergic D1 receptor. Prog. Neuropsychopharmacol. Biol. Psychiatry. 2018 Feb 2;81:468-76. 
Zhang Y, Jiang X, Qin C, Cuevas S, Jose PA, Armando I. Dopamine D2 receptors' effects on renal inflammation are mediated by regulation of PP2A function. Am. J. Physiol. Renal Physiol. 2016 Jan 15;310(2):F128-134.

Zhou X, Gan T, Fang G, Wang S, Mao Y, Ying C. Zeaxanthin improved diabetes-induced anxiety and depression through inhibiting inflammation in hippocampus. Metab. Brain Dis. 2018;33(3):705-11.

Zhou X, Zhang F, Hu X, Chen J, Tang R, Zheng K, et al. Depression can be prevented by astaxanthin through inhibition of hippocampal inflammation in diabetic mice. Brain Res. 2017 Feb 15;1657:262-8.

Zielinski MR, Kim Y, Karpova SA, McCarley RW, Strecker RE, Gerashchenko D. Chronic sleep restriction elevates brain interleukin-1 beta and tumor necrosis factor-alpha and attenuates brain-derived neurotrophic factor expression. Neurosci. Lett. 2014 Sep 19;580:27-31.

\section{Figures}
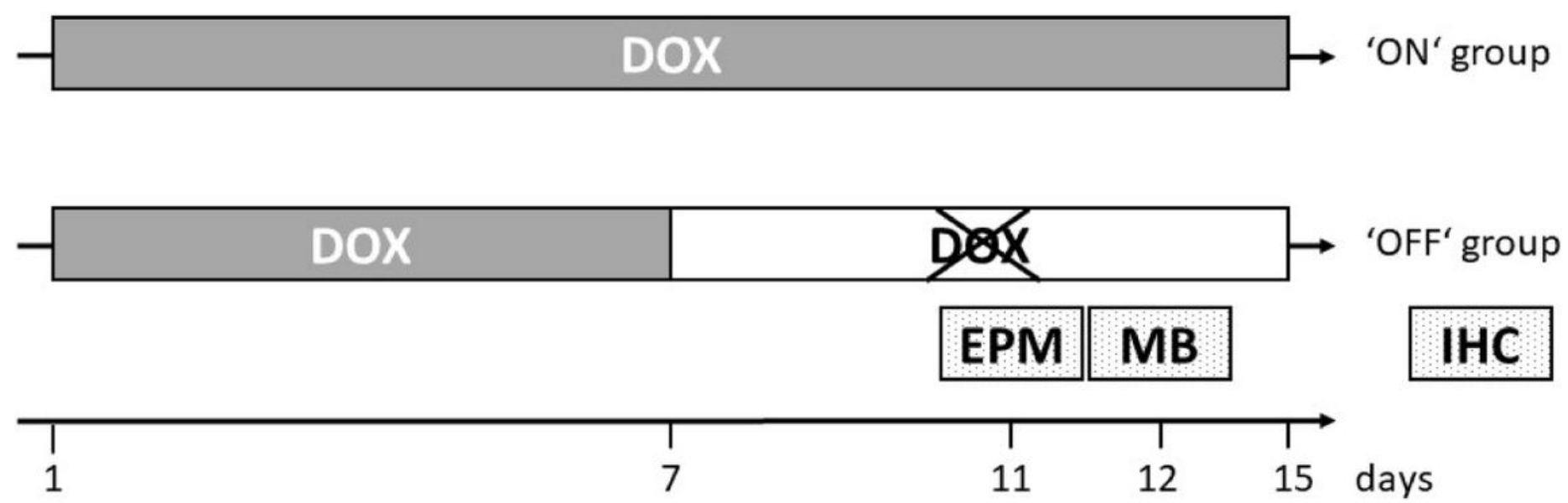

\section{Figure 1}

Experimental design. Glutamatergic neurons in the MPFC of rats were transduced with D1R or dsRed. After recovery from virus injection rats were treated for 7 continuous days with DOX to induce virus overexpression. In one half of the subjects, virus over-expression was maintained and is referred to as 'ON'. The 'OFF' group was not further provided with DOX after initial 7 days of virus over-expression. Behavioral experiments (EPM: Elevated Plus Maze and MB: Marble burying) were performed on day 11 and 12, respectively. Subjects were sacrificed via perfusion on day 15 and immunohistochemistry (IHC) was performed afterwards. 
A

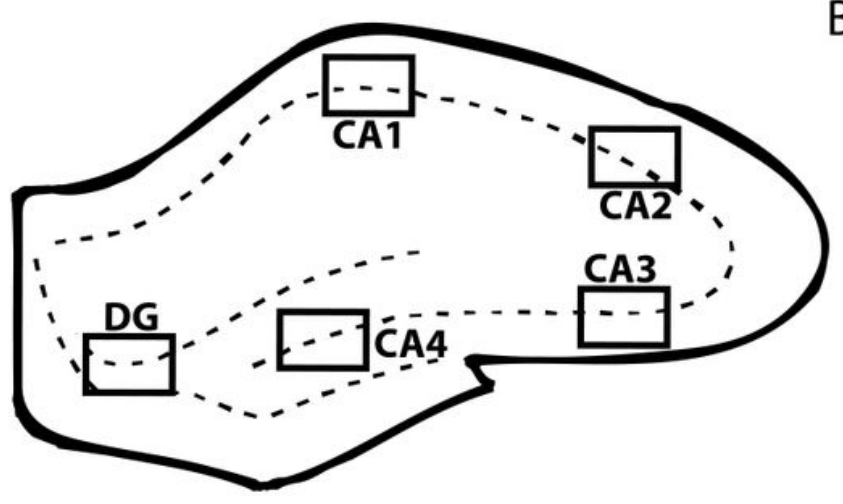

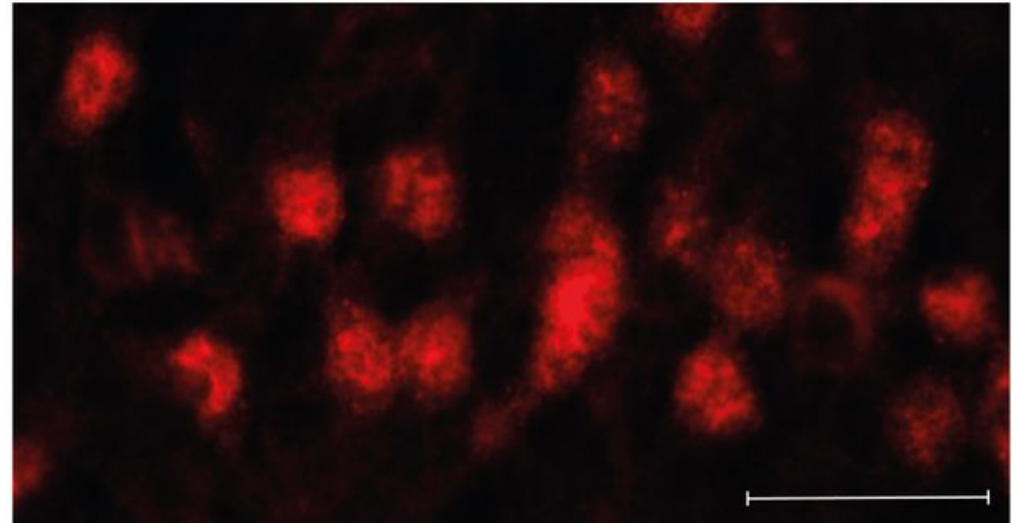

Figure 2

A) Schematic representation of the hippocampus including the regions of interest (hippocampal CA1, CA2, CA3, CA4 and DG). B) Immunhistochemical staining of IL-6-positive cells within the hippocampus. The circle represents a IL-6-positive cell. Scale bar represents $50 \mu \mathrm{m}$.

A

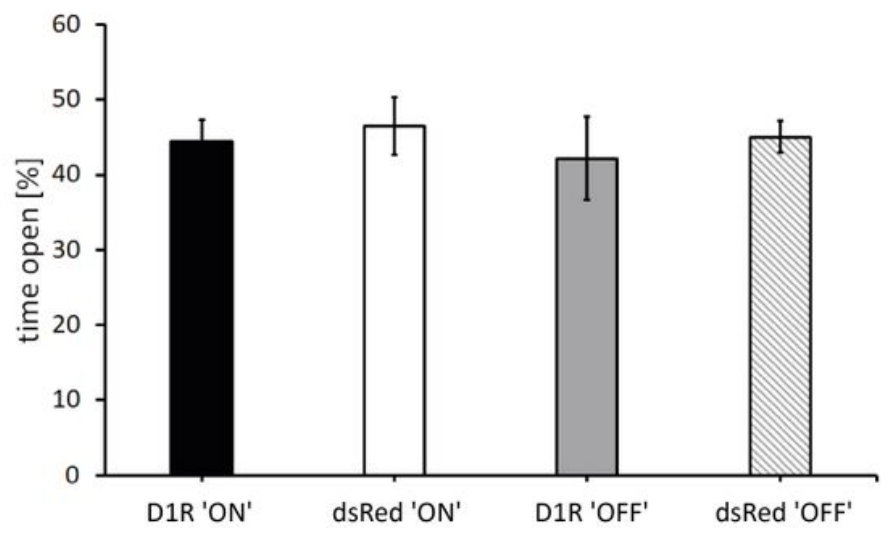

C

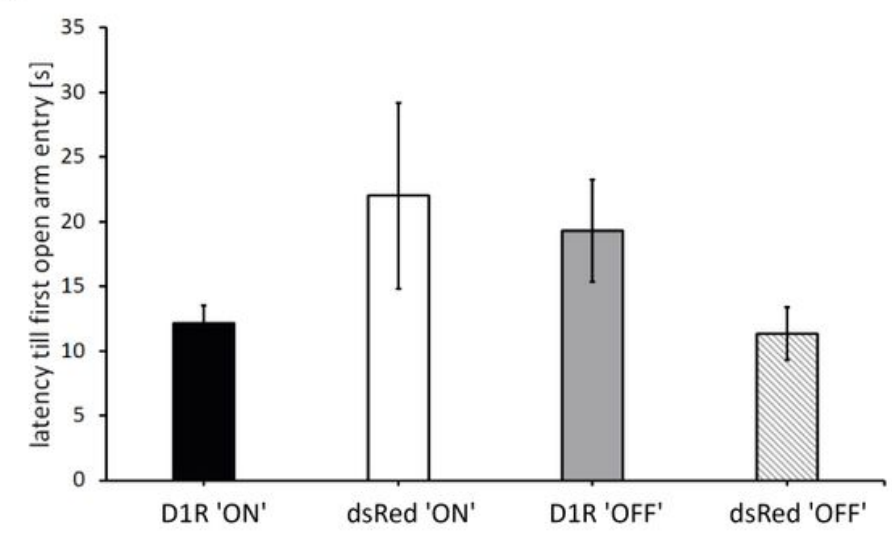

B

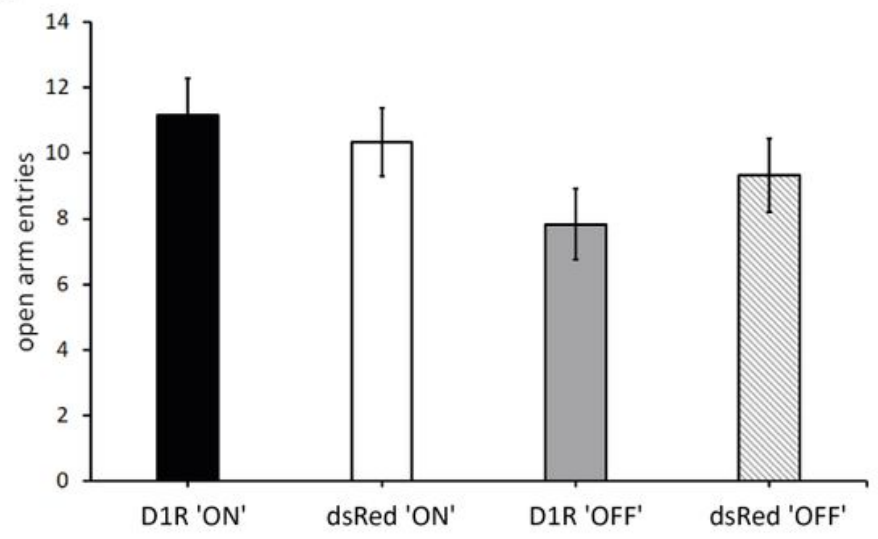

D

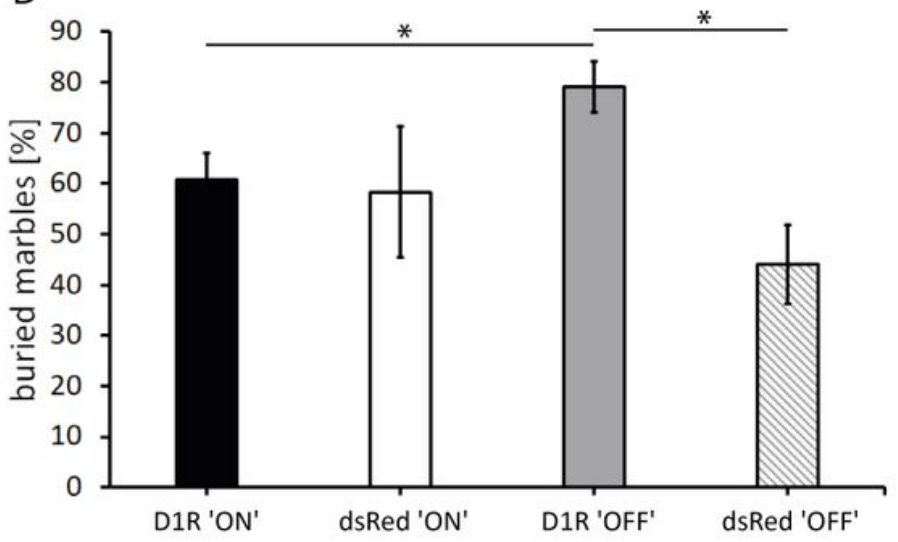

\section{Figure 3}

Anxiety behavior and compulsive activity accessed in the Elevated Plus Maze and Marble Burying paradigm indicated through the time in open arm, open arm entries and amount of buried marbles. Virus over-expression ('ON') is terminated ('OFF') following doxycycline removal. A) Anxiety as measured in the time spent in the open arm [\%]. B) Anxiety behavior was also determined as number of open arm entries. 
C) risky behavior as measured as latency till first open arm entry. D) D1R 'OFF' animals buried significantly more marbles than their control group (dsRed 'OFF') and D1R 'ON' subjects. Means \pm SEM are presented for $n=6$ subject for each group. * represent $p<0.05$ Bonferroni correction indicating significant differences between relevant groups.

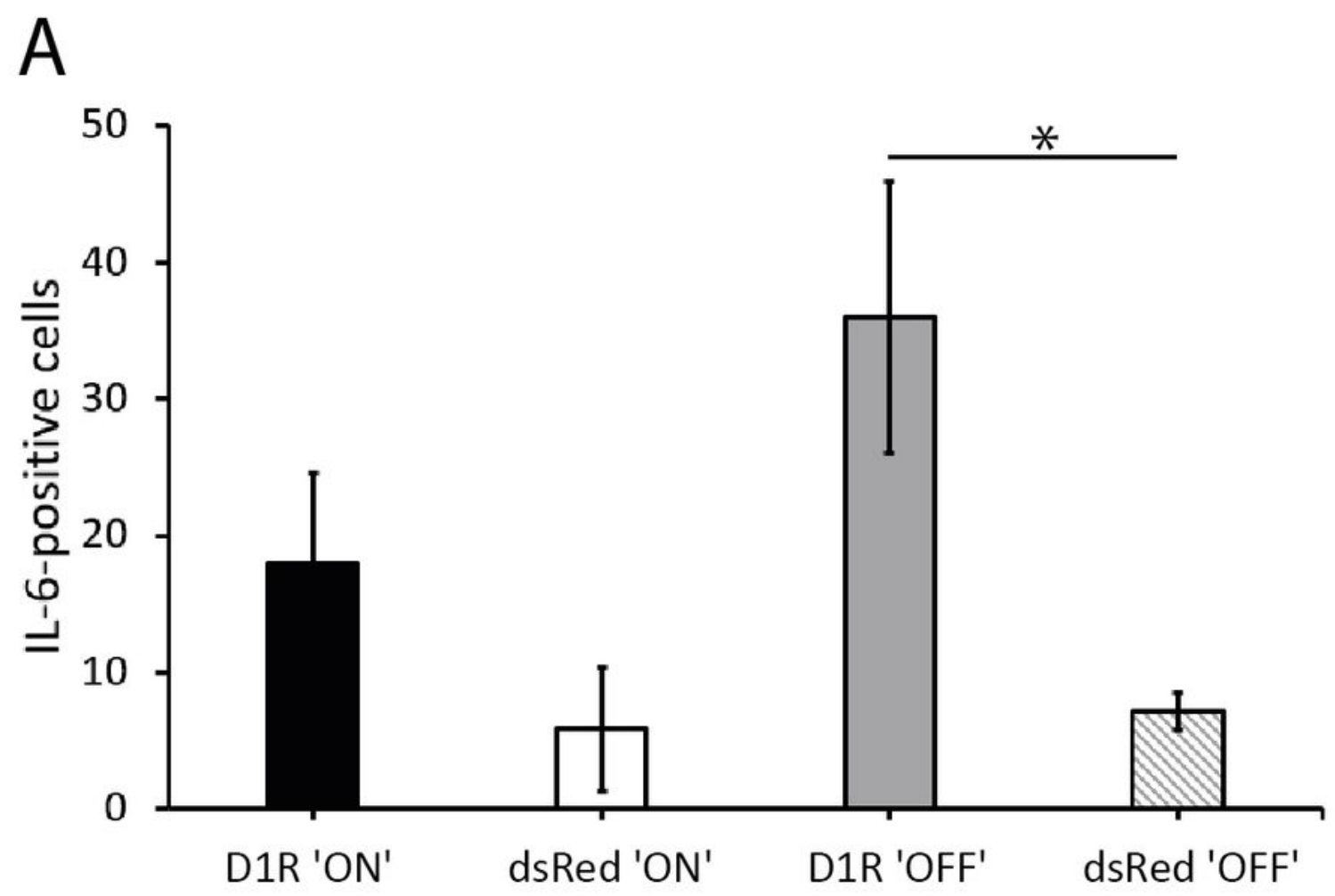

B

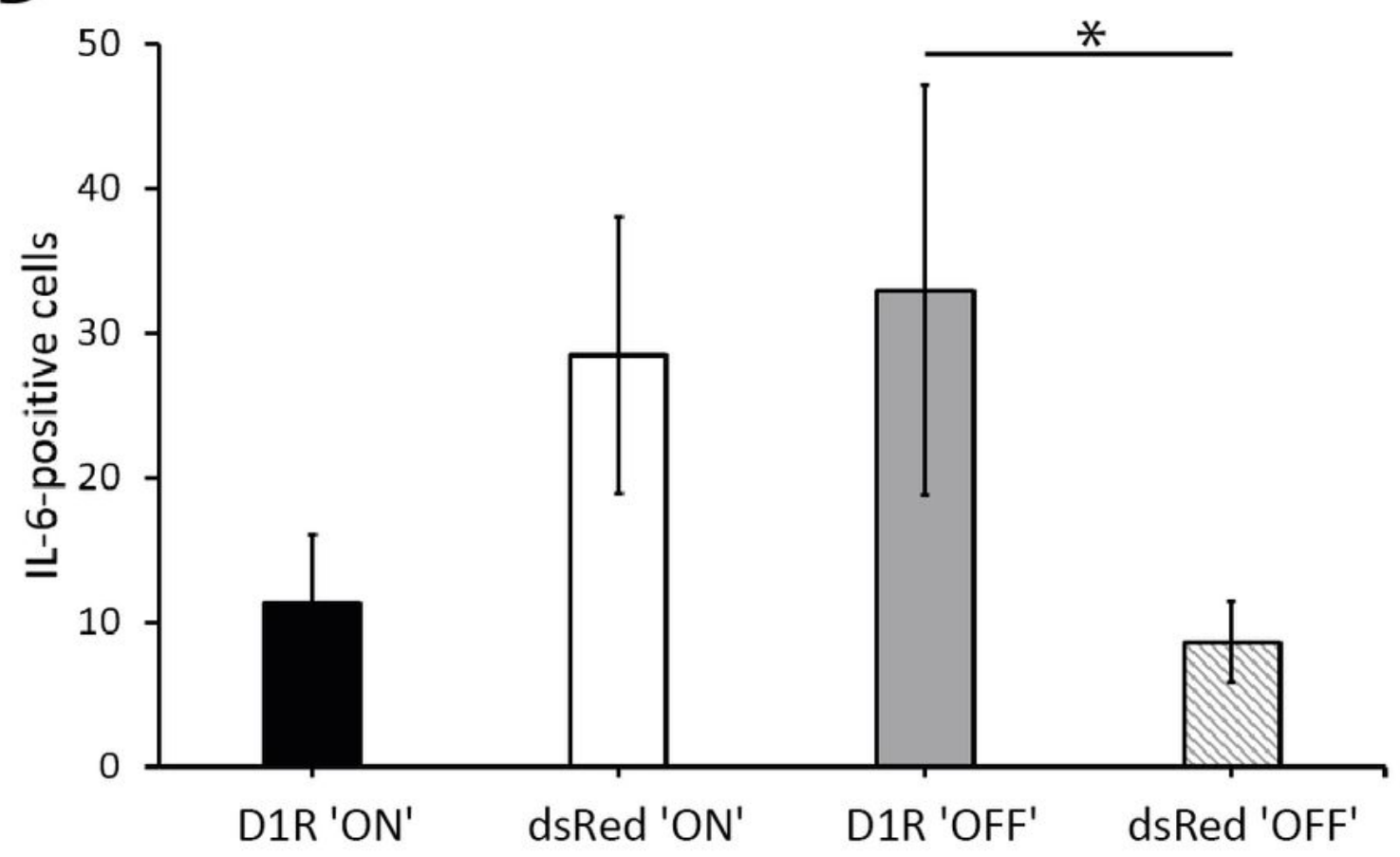

Figure 4 
IL-6-positive cells dependent on DAPI-positive cells. Virus over-expression ('ON') is terminated ('OFF') following doxycycline removal. A) Amount of IL-6-positive cells is significantly increased in D1R 'OFF' subjects compared to controls. B) No significant differences in the DG between groups. Means $\pm S E M$ are presented for $n=6$ subject for each group. * represent $p<0.05$ Bonferroni correction indicating significant differences between relevant groups.

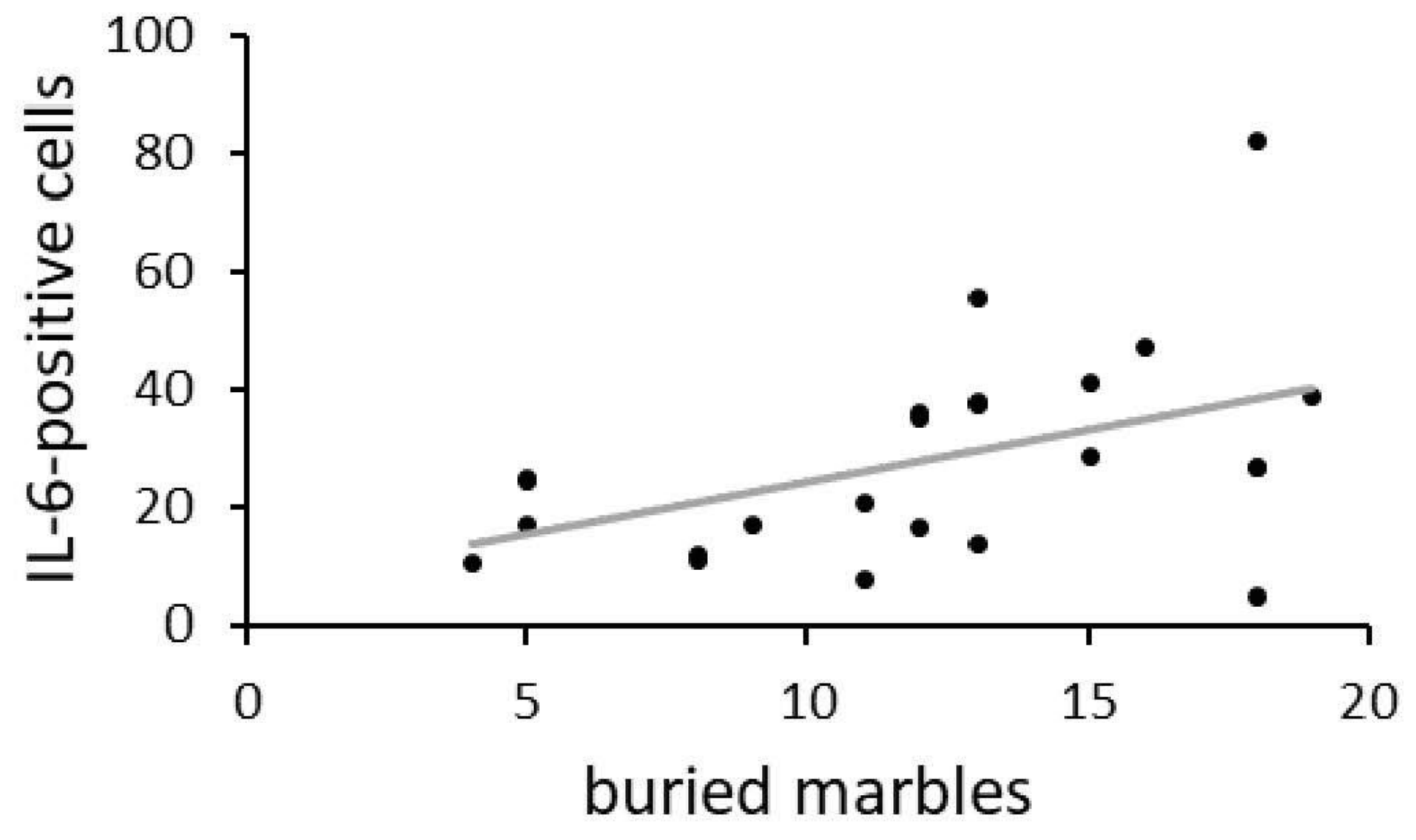

Figure 5

The amount of IL-6-positive cells dependent on DAPI-positive cells in the whole hippocampus correlate significantly positive with the amount of buried marbles representing anxiety behavior. Each dot represents one subject $(n=24)$. 